\title{
Correction to: Intelligent Human Systems Integration 2020
}

Tareq Ahram, Waldemar Karwowski, Alberto Vergnano,

Francesco Leali, and Redha Taiar

\section{Correction to:}

T. Ahram et al. (Eds.): Intelligent Human Systems Integration 2020, AISC 1131, https://doi.org/10.1007/978-3-030-39512-4

The original version of the book was inadvertently published with an incorrect spelling of the authors' names in Chapter 16 and an incorrect author's name in Reference 5 of Chapter 112. The book has been updated with the changes.

The updated versions of these chapters can be found at https://doi.org/10.1007/978-3-030-39512-4_16 https://doi.org/10.1007/978-3-030-39512-4_112 